\title{
Representações de Manaus no discurso publicitário
}

Lorena Maria Nobre TOMÁS

\section{Considerações iniciais}

Neste capítulo, temos como objetivo investigar a representação discursiva da cidade Manaus em um discurso publicitário, publicado no jornal A Crítica. A amostra está composta por um discurso da Agre/Aliança incorporadora, publicado no dia 23 de outubro, do ano de 2010. Os critérios que motivaram a seleção do anúncio foram: (1) que ocupasse a página inteira do jornal, ou seja, que se destacasse dos demais e (2) que fizesse referência à cidade de Manaus, por isso selecionamos a edição de um caderno especial publicado na véspera do aniversário da cidade. 
O campo da publicidade, do qual faz parte nossa amostra, vem ganhando cada vez mais espaço na sociedade contemporânea. Williams (2011, p. 260), já na década de 1960, destacava que "a publicidade não é mais uma mera forma de vender produtos, mas sim uma parte genuína da cultura de uma sociedade confusa”. Seu crescimento foi tamanho que não se pode uma sociedade capitalista funcionar sem ela. Por ocupar tal posição, a publicidade tem recebido a atenção de pesquisadores de diversas áreas, como da Teoria da Comunicação, dos Estudos Culturais, da Retórica e da Análise do Discurso. É nessa última que nos situamos com intuito de focalizarmos as representações discursivas presentes nessas produções, uma vez que o discurso publicitário, apesar de tematizar principalmente o consumo, fornece uma espécie de retrato do social, que nos possibilita compreender melhor a sociedade contemporânea, em particular, seus hábitos, costumes e valores.

Para a realização deste trabalho, fundamentamo-nos na Análise do Discurso (doravante AD), em sua perspectiva enunciativo-discursiva, conforme proposta por Maingueneau (1997, 2004, 2008a, 2008b, 2013, 2015). A análise está assentada, assim, nos pressupostos teórico-metodológicos dessa disciplina, que têm se mostrado um poderoso dispositivo de leitura, inclusive de gêneros multimodais. Considerando essas novas tendências, mobilizamos, do quadro da $\mathrm{AD}$, as categorias de interdiscurso, gênero de discurso e cenografia.

Realizamos ainda uma interface com os Estudos Culturais, a fim de situarmos o campo da publicidade e a noção de cultura, que são relevantes para a problemática aqui investigada. Para tanto, recorremos aos estudos de Williams (2011) e Bauman (2005; 2013).

Este capítulo encontra-se dividido em três seções. A primeira é dedicada às condições sócio-históricas e culturais de produção do discurso, na qual refletimos sobre o campo do discurso publici- 
tário e situamos o jornal A Crítica na sociedade de Manaus, explicitando alguns dados históricos da cidade. Na segunda, dedicada aos pressupostos teórico-metodológicos da $\mathrm{AD}$, apresentamos as categorias de análise selecionadas para este trabalho. Por fim, na terceira, procedemos à análise discursiva da amostra.

\section{Condições sócio-históricas e culturais de produção do discurso}

Para recuperar as condições sócio-históricas e culturais de produção do discurso aqui analisado, apresentamos as circunstâncias históricas mais pontuais em relação à publicação da amostra e uma perspectiva acerca do funcionamento do campo publicitário. Para tanto, recorremos às discussões apresentadas pelos Estudos Culturais, mais especificamente às reflexões de Williams (2011). Em seguida, situamos o jornal A Crítica no contexto social de Manaus e apresentamos um breve panorama da cidade. Dessa forma, pretendemos apreender as coerções próprias desse discurso, assim como o lugar social ocupado pelos enunciadores.

Segundo Williams (2011, p. 252), só é possível compreender a publicidade se "desenvolvermos um tipo de análise total no qual os fatos econômicos, sociais e culturais forem nitidamente relatados". Seguindo essa observação, o autor discute o desenvolvimento da publicidade, mencionando três momentos principais: no século XVII, com o aparecimento dos jornais, a publicidade começa a surgir de forma mais organizada; no século XVIII e XIX, com a Revolução Industrial e com a transformação dos meios de comunicação, aumenta em quantidade. Mas a chamada "nova publicidade" surge apenas no final do século XIX e início do XX, pela transformação a partir do capitalismo monopolista. 
De acordo com Williams (2011), a mais significativa transformação da publicidade ocorre devido à grande depressão entre os anos de 1875 a 1890. Na virada do século, já era reivindicada como profissão, mas ainda se apresentava como uma continuidade em relação aos seus antigos métodos, cujo foco era a exaltação da qualidade e do preço do produto. É apenas após a Primeira Guerra Mundial que uma nova característica irá se evidenciar: a "publicidade psicológica”. O apelo psicológico do patriotismo foi utilizado como recurso para o chamamento de homens para a guerra. Após esse período, esse novo padrão de adesão passou a ser utilizado para vender todo tipo de produto.

Consideramos ainda que a função da publicidade vai além da venda de bens de consumo ou de serviço. Segundo Rocha (2006), basta observarmos que o consumo de anúncios é muito superior ao de produtos:

Podemos pensar que em cada anúncio vendem-se, significativamente, mais estilos de vida, visões de mundo, sensações, emoções, relações humanas do que os bens de consumo efetivamente anunciados. Produtos e serviços são vendidos para quem pode comprar; os anúncios, entretanto, são vendidos indistintamente (ROCHA, 2006, p. 16).

Nesse sentido, no que toca às representações sociais, o estudo da publicidade tornou-se fundamental a partir da consolidação do capitalismo monopolista.

Após esse breve resgate da constituição do campo publicitário, passamos às condições sócio-históricas de produção mais específicas do discurso aqui analisado. A amostra que selecionamos foi 
publicada no jornal A Crítica, no dia 23 de outubro, de 2010. Esse jornal foi fundado por Umberto Calderaro Filho em $1946^{13}$ e está até hoje sob o comando de sua família. Pertence à Rede Calderaro de Comunicação, da qual fazem parte a TV A Crítica, afiliada da Rede Record, as rádios A Crítica FM e Jovem Pan FM Manaus, o periódico popular de formato tabloide Manaus Hoje, entre outros veículos. O jornal $A$ Crítica figura entre os de maior circulação na cidade de Manaus com uma tiragem ${ }^{14}$ média de 23 mil exemplares de segunda-feira a sábado e $35 \mathrm{mil}$ aos domingos. O perfil dos leitores do jornal é, em relação ao sexo, 55\% masculino e $45 \%$ feminino; em relação à faixa etária, $17 \%$ até 24 anos e $83 \%$ acima de 25 ; e, no que se refere à classe, $17 \% \mathrm{~A}$ e B, $50 \% \mathrm{C}$ e $33 \% \mathrm{D}$ e $\mathrm{E}$.

Desde 2003, A Crítica elabora um Caderno Especial em comemoração ao aniversário de Manaus. Esse caderno não possui estrutura fixa, mas está organizado em torno da temática do aniversário da cidade. Considerando, portanto, essa temática, recuperamos aqui alguns dados históricos relevantes dessa capital.

Manaus, capital do Estado do Amazonas, encontra-se à margem esquerda da do rio Negro e possui uma população estimada de 2.094.391 $1^{15}$, sendo considerada o sétimo município mais populoso do Brasil. Foi fundada em 1669 pelos portugueses como Forte São José do Rio Negro, cujo objetivo era proteger o norte do Brasil das invasões espanholas. No entorno do Forte, havia várias tribos

13 Apesar de ter sido fundado em 4 de maio de 1946, seu fundador escolheu a data de 19 de abril de 1949 para comemorar o aniversário do jornal, pois é a data que marca a independência do periódico. (LOPES, 2010, p. 52). Essa independência refere-se à aquisição de equipamentos.

14 Informação concedida à pesquisadora pelo Departamento de Circulação do jornal A Crítica em novembro de 2018. Outras informações disponíveis em: http://cidades.ibge.gov.br/xtras/perfil.php?codmun=130260. Acesso em: $12 \mathrm{de}$ junho de 2017.

15 De acordo com dados do IBGE de 2016. Disponível em: http://cidades.ibge.gov. br/xtras/perfil.php?codmun=130260. Acesso em: 12 de junho de 2017. 
indígenas, sendo uma delas a dos manaós, conhecida por resistirem à dominação portuguesa. Foi esse grupo indígena, já extinto, quem deu origem ao nome da cidade. Em 1832, foi elevada à categoria de Vila de Manaos e somente em 24 de outubro de 1848 passa a ser reconhecida como cidade. Considera-se, portanto, 24 de outubro como o dia de seu aniversário, mas a sua idade é contada a partir do ano da fundação do Forte. Por isso, considera-se que Manaus tem hoje 349 anos.

De sua história, destacamos ainda dois momentos fundamentais: o período áureo da borracha (1890-1920) e a implantação da Zona Franca de Manaus (ZFM) em 1967. O primeiro representa o grande surto de urbanização da cidade, devido aos recursos advindos da economia do látex, no qual a cidade ficou conhecida como "Paris dos Trópicos". Nesse momento, vieram para a região muitos nordestinos e europeus. $\mathrm{O}$ segundo também representa um momento de aceleração do processo de urbanização, agora, com o incentivo ao desenvolvimento da indústria e do comércio. Com isso, houve outro grande fluxo migratório, fazendo com que a população de Manaus aumentasse rapidamente e a cidades crescesse desordenadamente. Na década de 1960, por exemplo, a população de Manaus era de 175.343 mil habitantes e, na de 1980, passou para $642.492 \mathrm{mil}^{16}$.

Esses dois momentos fundamentais da história de Manaus, de fato, transformou a cidade em objeto de interesse de empresas e agências de publicidade, não apenas para vender produtos e serviços, mas também para incutir estilos de vida, conforme observou Rocha (2006). Diante disso, as práticas discursivas do campo da publicidade, muitas vezes, tornam visíveis representações estereotipadas de Manaus. De maneira geral, visam a construir represen-

16 De acordo com dados do IBGE. Disponível em: http://www.censo2010.ibge. gov.br/sinopse/index.php?dados=6\&uf=00. Acesso em: 12 de junho de 2017. 
tações diversas daquelas que atravessam o ethos coletivo do povo do Amazonas, em particular, daqueles, brasileiros ou não, que recordam da importância do Estado apenas por sua floresta tropical e sua biodiversidade. Diante dessas questões, a $\mathrm{AD}$ tem contribuído por "relacionar a estruturação dos textos aos lugares sociais que os tornam possíveis e que eles tornam possíveis." (MAINGUENEAU, 2015, p. 47). A noção de "lugar social" para essa disciplina não se refere ao lugar empírico, mas às posições ocupadas pelos sujeitos no discurso. Além disso, "o objeto da $\mathrm{AD}$ não são nem os funcionamentos textuais, nem a situação de comunicação, mas o que os amarra por meio de um dispositivo de enunciação simultaneamente resultante do verbal e do institucional." (MAINGUENEAU, 2015, p. 47). Após essa discussão das condições sócio-históricas de produção, passamos a apresentar os pressupostos teórico-metodológicos fundamentais para essa análise.

\section{Pressupostos teórico-metodológicos da Análise do Discurso}

A AD, que surgiu na década de 1960, é uma disciplina que tem grande aceitação entre pesquisadores de diversas áreas e correntes. Costuma-se dizer que ela é uma disciplina marcada por sua heterogeneidade. Por isso, faz-se necessário explicitar aqui nossa filiação teórica, que é a Análise do Discurso de linha francesa, em sua perspectiva enunciativo-discursiva, conforme as propostas de Maingueneau (1997, 2004, 2008a, 2008b, 2013, 2015). Nesta seção, abordamos primeiramente a noção de interdiscurso, em seguida, retomamos o quadro das cenas de enunciação, com destaque para a categoria de cenografia e, por fim, a noção de gêneros de discurso deste autor. 


\section{O primado do interdiscurso}

Por considerar imprecisa a noção de interdiscurso que se utilizava na $\mathrm{AD}$ em sua fase inicial, Maingueneau (2008a) aprofunda a discussão sobre a noção e propõe apreendê-la a partir de uma tríade, que pretende ser mais operacional: o universo discursivo, o campo discursivo e o espaço discursivo.

O universo discursivo é compreendido como o conjunto de formações que coexiste em uma dada conjuntura. Apesar de ser finita, não pode ser apreendida em sua globalidade, por isso é de pouca utilidade para o analista. No entanto, mostra-se relevante por apresentar o horizonte a partir do qual o analista deve recortar os campos discursivos.

O campo discursivo, por sua vez, corresponde ao conjunto de formações discursivas que se delimitam reciprocamente em uma determinada região do universo discursivo. As formações discursivas (doravante FDs) podem se encontrar em relação de concorrência, como confronto aberto, aliança ou neutralidade aparente. São normalmente citados como exemplos o campo político, o filosófico e o religioso. No entanto, Maingueneau (2008a) adverte que o recorte do universo discursivo em campos não passa de uma abstração necessária e que as fronteiras entre os campos não são bem definidas e evidentes. Assim, o analista deve estar ciente de que deverá fazer escolhas e enunciar hipóteses, visto que não basta recorrer ao saber histórico para propor uma determinada divisão. Essa noção é interessante para a $\mathrm{AD}$ porque é no interior do campo que os discursos se constituem.

Por fim, o espaço discursivo é entendido como o subconjunto das FDs de um dado campo discursivo, que o analista julgar necessário pôr em relação de acordo com seus objetivos de pesquisa. Esse é um procedimento que requer algumas escolhas do analista 
a partir de seu conhecimento do corpus e de seu saber histórico. $\mathrm{O}$ analista estabelecerá hipóteses que poderão ser confirmadas ou não no desenvolver da pesquisa.

Nessa perspectiva, o interdiscurso é anterior ao discurso e não está presente apenas quando é possível localizá-lo na materialidade linguística, ao contrário, o Mesmo do discurso e seu Outro são indissociáveis:

No espaço discursivo, o Outro não é nem um fragmento localizável, uma citação, nem uma entidade externa; não é necessário que ele seja localizável por alguma ruptura visível da compacidade do discurso. Ele se encontra na raiz de um Mesmo sempre já descentrado em relação a si próprio, que não é em momento algum passível de ser considerado sob a figura de uma plenitude autônoma (MAINGUENEAU, 2008a, p. 36-37).

Por isso, a identidade discursiva deve ser pensada na relação com o Outro, e o analista, por sua vez, deve apreender não uma $\mathrm{FD}$, mas a interação entre elas.

Dessa breve apresentação de alguns princípios básicos da $\mathrm{AD}$, destacamos a importância para este trabalho das noções de condições sócio-histórica de produção e de interdiscurso para a análise do corpus. Mobilizamos também para a análise a categoria de cenografia e de gênero de discurso.

\section{Cenas de enunciação}

A noção de cenas de enunciação, proposta por Maingueneau (2008b; 2013; 2015), tem se mostrado produtiva para a pesquisa em AD. Trata-se de uma tríade composta pela cena englobante, 
cena genérica e cenografia. A cena englobante corresponde ao tipo de discurso, ou seja, é o que nos permite classificar um determinado gênero como pertencente ao discurso acadêmico, religioso, político etc. Essa classificação resulta, segundo Maingueneau (2015, p. 118), "do recorte de um setor da atividade social caracterizável por uma rede de gêneros de discurso". Neste trabalho, por exemplo, o corpus é composto por um discurso que se textualiza no gênero anúncio publicitário, que pertence ao discurso publicitário e, portanto, está submetido às restrições desse campo, como já foi apresentado no item sobre as condições sócio-históricas de produção. Ao determinar a cena englobante publicitária, o leitor aciona imediatamente a finalidade do gênero e os papéis que enunciador e co-enunciador devem desempenhar.

A cena genérica, por sua vez, está relacionada à noção de gênero de discurso, mas não se equivalem. As cenas genéricas são mais abrangentes. Para Maingueneau (2015, p. 120), elas "funcionam como normas que suscitam expectativas". O teórico elenca sete características que estão associados a essa cena, quais sejam: supõe-se que o locutor seja capaz de atribuir finalidades à atividade da qual participa; os parceiros da enunciação desempenham diferentes papéis de acordo com cada gênero; há lugares/espaços apropriados para o sucesso dos gêneros; eles têm modos diferentes de inscrição na temporalidade; o gênero é indissociável de seu modo de existência material, ou seja, de seu suporte; as partes e o modo de encadeamento dos gêneros podem ser mais ou menos variáveis; cada gênero de discurso impõe determinadas restrições quanto aos recursos linguísticos (MAINGUENEAU, 2015). Essas duas cenas correspondem ao quadro cênico, que é o espaço estável onde o enunciado adquire sentido. No entanto, segundo Maingueneau (2013, p. 97, grifo do autor), "não é com o quadro cênico que se confronta o leitor, mas com a cenografia", o quadro cênico é assim deslocado para um segundo plano. 
Por considerar que as normas do quadro cênico não são suficientes para a compreensão das singularidades do texto, Maingueneau $(2008 b, 2013,2015)$ propõe a noção de cenografia. Para ele, "enunciar não é apenas ativar as normas de uma instituição de fala prévia; é construir sobre essa base uma encenação singular da enunciação: uma cenografia” (MAINGUENEAU, 2015, p. 122, grifo do autor). Ela não é determinada pelo tipo ou gênero de discurso, mas instituída no processo da enunciação. Apesar de incluir o cenário, a cenografia não pode ser resumida a ele.

Alguns gêneros de discurso possuem cenografias mais estáveis, outros mais instáveis. Os gêneros acadêmicos, por exemplo, apresentam cenografias fixas, limitando-se à da cena genérica. Por outro lado, os gêneros publicitários são, normalmente, surpreendentes quanto à cenografia mobilizada. O discurso da publicidade busca as que melhor se adéquam ao produto a ser anunciado, bem como à "mensagem" a ser passada ao co-enunciador-consumidor. No entanto, mesmo nos gêneros publicitários, há cenografias recorrentes para anunciar determinados produtos. É o caso da maior parte dos anúncios de margarina que utilizam a conhecida cenografia da conversa em família no café da manhã. A cenografia utilizada é a que se julga mais adequada para suscitar a adesão dos coenunciadores e se liga à finalidade do gênero de discurso.

A cenografia não é imposta pelos gêneros de discurso, ela é construída pela própria enunciação. Mesmo assim, ela não é totalmente livre, visto que sofre as restrições próprias de cada gênero, como será visto a seguir ao abordarmos o modo de genericidade dos gêneros instituídos. 


\section{Gêneros de discurso}

A noção de gênero de discurso vem sendo abordada em diferentes perspectivas principalmente a partir da década de 1980. Essa noção não esteve no centro das preocupações da $\mathrm{AD}$ desde o seu início, mas desempenha lugar privilegiado nas discussões atuais. Adotaremos para este trabalho a perspectiva de Maingueneau (2004, 2013, 2015), que, mesmo considerando a noção de gênero de discurso problemática, reconhece sua importância. Ao estabelecer a diferença entre unidades tópicas e não tópicas do discurso ${ }^{17}$, Maingueneau (2015) afirma que as unidades tópicas se articulam em torno da categoria de gênero de discurso. Este último é compreendido por ele como instituição de fala, dispositivo de comunicação sócio-historicamente determinado.

Para Maingueneau (2015), os gêneros de discurso são os átomos da atividade discursiva, enquanto os tipos de discurso são as unidades de classe superior. Assim, um romance é um gênero de discurso que faz parte de uma unidade mais ampla, o discurso literário. Para o autor, a noção de tipo de discurso ainda deve ser refinada, mas alerta que ela só faz sentido se permanecer vaga.

Quanto à classificação dos gêneros, Maingueneau (2004) distinguiu, inicialmente, três regimes de genericidade: gêneros autorais, rotineiros e conversacionais. O primeiro grupo compreende os gêneros determinados pelo próprio autor ou editor, são os que recebem etiquetagem. São comuns nos tipos de discurso filosófico, literário, religioso e jornalístico. $\mathrm{O}$ segundo engloba gêneros como entrevista radiofônica, consulta médica, sentença jurídica, nos quais os "papéis desempenhados pelos parceiros da comunicação,

17 As unidades tópicas são compreendidas como já pré-recortadas pelas práticas sociais, por isso se articulam em torno da categoria de gênero de discurso, enquanto as não tópicas são as unidades construídas pelo pesquisador (MAINGUENEAU, 2015, p. 66). 
as finalidades da atividade, as circunstâncias nas quais a comunicação intervém são fixadas a priori e permanecem normalmente imutáveis durante o ato de comunicação" (MAINGUENEAU, 2015, p. 110). O terceiro se refere às interações conversacionais, que não estão ligadas a lugares institucionais e possuem características muito variáveis, o que leva alguns estudiosos inclusive a questionarem se a noção de gênero se aplica nesse caso.

Em trabalhos posteriores, Maingueneau (2004, 2015) passa a considerar mais pertinente fazer a distinção apenas entre regime instituído e conversacional. O regime instituído, para o qual a noção de gênero de discurso tem se mostrado pertinente, engloba os gêneros autorais e rotineiros apresentados anteriormente. A maioria dos trabalhos em AD está voltada para esse regime. Num regime conversacional, no entanto, a flexibilidade e a instabilidade predominam e a "categorização em gênero de discurso é altamente problemática" (MAINGUENEAU, 2015, p. 112). Vale ressaltar ainda que, com a evolução da tecnologia da comunicação, é cada vez mais difícil estabelecer limites claros entre os regimes.

No que se refere ao modo de genericidade dos gêneros instituídos, Maingueneau (2004, 2015) apresenta uma classificação, em quatro tipos, para mostrar que a relação entre cena genérica e cenografia varia de acordo com o gênero de discurso envolvido: 1) gêneros instituídos de modo I - estão pouco sujeitos à variação; 2) gêneros instituídos de modo II - são gêneros rotineiros que seguem as restrições de sua cena genérica, mas apresentam cenografias endógenas singulares; 3 ) gêneros instituídos de modo III - englobam gêneros que se caracterizam por exigirem cenografias exógenas; 4) gêneros instituídos de modo IV - referem-se aos gêneros propriamente autorais, aos quais o autor/editor associa uma etiqueta. 
Nossa amostra pertence, portanto, à cena englobante do discurso publicitário e sua cena genérica à do anúncio publicitário. De acordo com a categorização de Maingueneau (2015), esse gênero faz parte do regime instituído de modo III, que se caracteriza pela mobilização de cenografias variadas. Considerando ainda que os elementos não verbais ganham destaque nessas cenografias, refletimos também sobre o fenômeno da multimodalidade na perspectiva enunciativo-discursiva da $\mathrm{AD}$.

A multimodalidade não é um fenômeno novo, ou seja, um texto escrito, mesmo sem a presença de imagens, é multimodal, pois envolve vários elementos como layout da página, tamanho e tipo de fonte que também são constitutivos do sentido do discurso. No entanto, com o desenvolvimento das novas tecnologias da comunicação, a quantidade de textos multimodais, ou seja, que englobam mais modalidade de linguagem (palavra, imagem, som, movimento), aumentou consideravelmente.

Para Maingueneau (2008a), a prática discursiva é intersemiótica, pois envolve outros domínios além do linguístico, como o pictórico, o musical etc. Nesse sentido, o autor propõe ampliar a noção de "texto" para os diversos tipos de produções semióticas que pertencem a uma prática discursiva. Tais práticas continuam sendo objeto de interesse da $\mathrm{AD}$, pois "o pertencimento a uma mesma prática discursiva de objetos derivados de domínios semióticos diferentes exprime-se em termos de conformidade a um mesmo sistema de restrições semânticas" (MAINGUENEAU, 2008a, p. 138). Nesse sentido, o autor destaca a pertinência dos pressupostos teórico-metodológicos da $\mathrm{AD}$ para a análise das práticas intersemióticas, visto que elas também estão sujeitas aos sistemas de restrições semânticas.

Em sua publicação brasileira mais recente, Maingueneau (2015) volta a discutir a multimodalidade ao refletir sobre as novas 
textualidades que se desenvolveram a partir da segunda metade do século XX. Para o autor,

a porção dos enunciados "escritos" que acompanham elementos icônicos cresce sem cessar, o que afeta a própria noção de "texto", tanto que se fala às vezes, de "iconotexto" para designar as produções semióticas em que imagem e fala são indissociáveis (MAINGUENEAU, 2015, p. 160).

Essa reflexão nos mostra não exatamente que o termo "texto" deva mudar, mas que é impossível analisar um texto multimodal levando em consideração apenas a dimensão verbal, visto que a imagem não é algo acessório, mas constitutivo de sua totalidade.

Os gêneros publicitários mobilizam em suas cenografias maciçamente os recursos multimodais (imagem fixa ou móvel, som etc.). Em nossa amostra, extraída do jornal impresso, os recursos utilizados foram, sobretudo, imagem (fotografias) e tipologia da fonte, que serão analisados a seguir.

Feita essa incursão pelas categorias que foram mobilizadas em função de nossa amostra, passamos à análise do discurso selecionado. Antes disso, porém, realizamos uma breve contextualização da amostra.

\section{Contextualização da amostra}

Como já foi mencionado, o discurso aqui analisado foi extraído do jornal A Crítica, mais especificamente do Caderno Especial, publicado em homenagem ao aniversário da cidade de Manaus em 2010. Por questões de delimitação, analisamos apenas um anúncio 
publicitário, tomado como discurso. Por essa razão, faz-se necessário recuperar aqui o contexto mais imediato de sua publicação.

Nessa edição, o jornal completo possui 18 cadernos e 144 páginas. A manchete da editoria Cidades, destinada às informações do dia a dia da cidade, aborda a temática da maior seca já vivida na região: o chapéu ${ }^{18}$ anuncia "Ribeirinhos no seco", e o título, "Mudança de hábito". As principais notícias giravam em torno, portanto, de algo incomum à região, uma grande seca, e suas consequências. Como será visto a seguir, o Caderno Especial não explora essa problemática.

O Caderno Especial, por sua vez, possui 32 páginas e está organizado em torno de dois tipos de matérias. A primeira parte foi destinada à apresentação do regulamento de uma espécie de jogo, uma "caça ao tesouro" e dos locais onde estão escondidos os vouchers, que foram colocados em seis pontos turísticos da cidade. Quem encontrasse os vouchers receberia prêmios. As primeiras matérias do caderno apresentam a história e as funções desses locais. A segunda parte foi totalmente destinada à apresentação de relatos de personagens (empresários, médicos, políticos etc.) que vieram de outros lugares e se fixaram em Manaus. Desses 37 personagens que migraram para Manaus, 35 vieram de outros estados brasileiros e dois deles de outros países. Há aqui um dado significativo e que merece ser explorado em trabalhos futuros: as personagens escolhidas para falar sobre Manaus foram os migrantes, sobretudo de outros estados do país, nesta edição não se dá voz aos nativos tampouco aos migrantes intermunicipais.

18 No jargão jornalístico, "chapéu” é uma palavra ou expressão utilizada acima do título, mas com fonte menor, para caracterizar o tema ou a personagem da notícia. 
Vejamos algumas observações quanto à disposição do anúncio em seu mídium ${ }^{19}$, a folha de jornal impressa. Nas 32 páginas desse caderno, há 28 anúncios dispostos em 27 páginas: 17 ocupam o espaço de 16 meias páginas do jornal; 4 ocupam 1/3 da página e 7 ocupam a página inteira. Nesta edição, os anúncios começam a surgir a partir da página 5 , dividindo o espaço com o relato dos personagens entrevistados. Destacamos aqui a inter-relação do discurso publicitário com o jornalístico mencionado por Williams (2011) ainda na década de 1960.

Concordamos com Williams (2011) quando ele se opõe à classificação da publicidade como um serviço, ela vai muito além do contexto comercial. A publicidade "é, em um certo sentido, a arte oficial da sociedade capitalista moderna: é o que 'nós' colocamos em 'nossas' ruas e usamos para preencher metade de 'nossos' jornais." (WILLIAMS, 2011, p. 252). Destacamos, assim, o papel central dessa instituição nos meios de comunicação e na sociedade moderna de um modo geral.

Tendo em mente as condições sócio-históricas de produção, bem como essa contextualização mais imediata da amostra, iniciamos a análise propriamente do discurso, que é materializado como um anúncio publicitário da construtora Agre e Aliança Incorporadora. Ele ocupa a página inteira e está localizado na última folha do jornal, pág. 32, do Caderno Especial.

19 Modo de manifestação material dos discursos, suporte, meio (MAINGUENEAU, 2013, p. 81). 


\section{Análise discursiva da amostra}

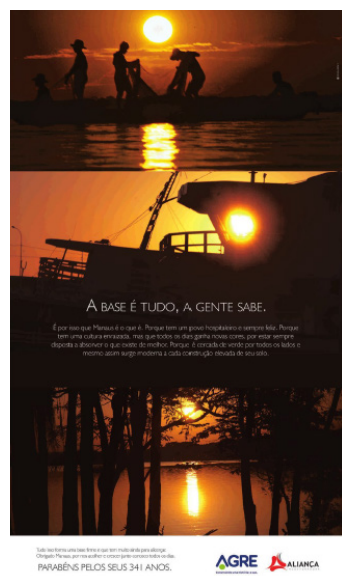

Figura 1. Amostra

A cenografia do anúncio inclui três fotos que destacam o pôr do sol em diferentes cenários. Na primeira, há referência ao elemento humano, representado pela figura dos ribeirinhos pescando com malhadeira ${ }^{20}$ em uma pequena canoa. Na segunda, enfoca-se uma fileira de barcos de madeira, típicos da região, ancorados em um porto. A terceira focaliza também o pôr do sol, mas com destaque apenas para as árvores e para o reflexo do sol no rio. Na sua dimensão imagética, a cenografia recorre à representação de elementos da natureza. Cada uma das três fotos poderia ser tomada como um cartão-postal não especificamente da cidade de Manaus, mas da região amazônica como um todo. Com esse destaque para a natureza, busca-se realçar os elementos próprios da região, como o "rio" e o "sol", recorrentes nas três imagens. Mesmo na segunda foto, em que o rio não aparece, ele está presente na figura dos barcos. Destacam-se também atividades próprias e tradicionais da região, como a pescaria artesanal e o transporte por barcos.

20 Rede de pesca utilizada pelos pescadores artesanais. 
No centro das imagens, há um título em caixa alta, acompanhado de um enunciado, transcrito abaixo. $\mathrm{O}$ texto é relativamente grande para os padrões do gênero anúncio publicitário encontrado na cultura brasileira:

\section{Recorte 1}

Texto (A)

\section{[1] A BASE É TUDO, A GENTE SABE.}

[2] É por isso que Manaus é o que é. Porque tem um povo hospitaleiro e sempre feliz. [3] Porque tem uma cultura enraizada, mas que todos os dias ganha novas cores, por estar sempre disposta a absorver o que existe de melhor. [4] Porque é cercada de verde por todos os lados e mesmo assim surge moderna a cada construção elevada de seu solo.

No rodapé do anúncio há ainda:

\section{Recorte 2}

Texto (B)

[5] Tudo isso forma uma base firme e que tem muito ainda para alicerçar. [6] Obrigado Manaus por nos acolher e crescer junto conosco todos os dias. 
A produção do gênero publicitário é, normalmente, atribuída a uma agência de publicidade, mas é o anunciante quem se responsabiliza pelo que foi nele enunciado. Para os casos em que o locutor é uma instituição, grupo conjuntural ou marca, Maingueneau (2015, p. 75) propõe a designação de "locutor coletivo". No discurso em questão, a locução pronominal "a gente" presente no título é preenchida com o nome de duas empresas do ramo imobiliário: a construtora Agre e a incorporadora Aliança, que, ao assumirem atributos antropomórficos, afirmam logo no título que "a base é tudo".

Nesse contexto, o termo "base" é ambíguo. Um dos sentidos é o de "base" como alicerce, a parte mais importante de uma construção, por exemplo. Esse sentido se evidencia quando o interlocutor reconhece os locutores do anúncio, que se mostram por suas logomarcas localizadas do lado direito, no rodapé do texto. Outro sentido possível é mais metafórico, toma-se "base" como aspecto essencial de algo, origem, princípio. Um dos aspectos dessa "base" é o que se chamou de "cultura enraizada" e que está em consonância com a representação imagética levantada inicialmente. Esse último sentido é confirmado pelo enunciado [5].

Os enunciados [5] e [6] são fundamentais para a construção da cenografia desse discurso. Como o Caderno Especial foi produzido em comemoração ao aniversário da cidade, o enunciador evoca, então, uma cenografia de felicitação à aniversariante. Em um primeiro momento, o discurso publicitário exaltou o que julga serem as qualidades da cidade e de sua população: [2] "povo hospitaleiro [...] sempre feliz", [3] "cultura enraizada, mas que todos os dias ganha novas cores [...]", [4] "cercada de verde por todos os lados e mesmo assim surge moderna [...]". Posteriormente, agradeceu dirigindo-se diretamente a Manaus: [5] "Obrigado Manaus por nos acolher [...]", em que se deixa entrever mais uma qualidade, a de 
"cidade acolhedora". Por fim, parabenizou a cidade como se dialogasse, mais uma vez, diretamente com ela e faz o fechamento da mensagem utilizando o recurso da caixa alta para dar destaque ao enunciado [6]: "PARABÉNS PELOS SEUS 341 ANOS". Manaus assume a função de um interlocutor e, assim como o locutor coletivo, apresenta características antropomórficas e representa um grupo, por isso, vamos chamá-la aqui de interlocutor coletivo. Quanto aos recursos linguísticos da cenografia, destacamos a presença do vocabulário próprio do mercado imobiliário: "base firme", "crescer", "alicerçar", "moderna”.

Ainda sobre os recursos linguísticos da cenografia, destacamos dois operadores argumentativos: "mas" e "mesmo assim". Maingueneau (1997) alerta-nos de que o estudo do vocabulário já ocupou lugar excessivamente amplo na $\mathrm{AD}$, mas que não deve ser negligenciado agora. Para ele, "o vocabulário encontra-se necessariamente situado no cruzamento de múltiplas instâncias, da cena enunciativa aos modos de coesão textual, passando pelo interdiscurso" (1997, p. 155). O léxico deve, portanto, ser apreendido em sua complexidade, dentro do que o autor chamou de uma semântica global. No discurso em estudo, os conectivos mencionados permitem-nos identificar os interdiscursos presentes, bem como alguns posicionamentos.

O enunciado [2] nos diz que: "É por isso que Manaus é o que é. Porque tem uma "cultura enraizada, mas que todos os dias <ganha novas cores $>$ ", por estar "sempre disposta a absorver o que existe de melhor". Ao afirmar o enraizamento da cultura, acionamos o pressuposto de sua rigidez e, de acordo com o posicionamento do discurso publicitário em foco, isso é visto como algo negativo, por isso, o argumento mais forte vem logo a seguir, depois da conjunção "mas": "<mas> que todos os dias < ganha novas cores>, por estar sempre disposta a absorver o que existe de melhor". "Ganhar 
novas cores" e "absorver o que existe de melhor" representa a flexibilidade tão valorizada no mundo globalizado. Como diz Bauman (2013, p. 27), "se você não quer afundar, deve continuar surfando, ou seja, continuar mudando, com tanta frequência quanto possível, o guarda-roupa, a mobília, o papel de parede, a aparência e os hábitos - em suma, você”.

Evidenciamos de fato a transformação pelo qual tem passado o conceito de cultura na modernidade líquida ${ }^{21}$. Como adverte Bauman (2013, p. 20), "a cultura hoje se assemelha a uma das seções de um mundo moldado como uma gigantesca loja de departamento em que vivem, acima de tudo, pessoas transformadas em consumidores". A ideia de cultura como algo que simplesmente pode ser comprado está fortemente presente no discurso publicitário, por isso, esse discurso rejeita a ideia de cultura como algo rígido e valoriza a flexibilidade. Quem está disposto "a absorver o que existe de melhor” está mais suscetível ao consumo.

Além disso, para vender um produto, a publicidade precisa atribuir sentido a ele. Segundo Williams (2011, p. 257), "não compramos apenas um objeto: compramos respeito social, discriminação, saúde, beleza, sucesso e poder para controlar nosso ambiente". Isso ocorre porque "possuímos um padrão cultural no qual os objetos não se bastam, mas devem ser validados, mesmo que apenas na fantasia por associações com significados sociais e pessoais [...]" (WILLIAMS, 2011, p. 252). Nesse discurso, a marca está associada à ideia de modernidade, como se evidencia no seguinte enunciado: [4] “[...] surge moderna a cada construção elevada de seu solo" e busca diferenciação, como se observa em: [3] "[...] absorver o que <existe de melhor>".

21 Bauman (2013, p. 16) usa a expressão "modernidade líquida” para denominar o formato atual da condição moderna, descrita por outros autores como "pós-modernidade", "modernidade tardia", "segunda modernidade", "hipermodernidade". 
No enunciado [4], "Porque é cercada de verde por todos os lados e <mesmo assim $>$ surge moderna a cada construção elevada de seu solo", o conectivo "mesmo assim" aciona, na forma do implícito, alguns interdiscursos muito recorrentes que afirmam o "atraso", o "subdesenvolvimento" da região, por considerarem a floresta, aqui representando pelo "verde", incompatível com a "modernidade". Nesse discurso, a modernidade é representada pela construção de prédios. Há ainda uma tentativa de conciliar o que na prática tem se mostrado inconciliável, pois a modernidade à que ele se refere está relacionada com a construção civil e, portanto, com o desmatamento.

Segundo Castro (2011), a noção de progresso foi reformulada na segunda metade do século XX, passando a ter uma noção modernista. O progresso foi reformulado como "desenvolvimento", definido em oposição a "subdesenvolvimento", deixando de representar a emancipação da humanidade. Castro (2011, p. 190) acrescenta que assim: "Todas as sociedades e culturas passam a ser analisadas e avaliadas de acordo com seu estado de desenvolvimento, ou seja, de acordo com sua aproximação a sociedades 'avançadas' do mundo ocidental".

\section{Considerações finais}

A análise desse discurso, materializado em anúncio publicitário, possibilitou-nos a identificação das seguintes representações discursivas de Manaus: cidade acolhedora, moderna e em pleno desenvolvimento/crescimento. Foi possível identificar também algumas representações da população da cidade: povo acolhedor, sempre feliz e de cultura flexível. 
Esse discurso atende às restrições próprias do Caderno Especial, mas sem se afastar das exigências do gênero anúncio publicitário. Como o Caderno Especial é todo voltado para a comemoração do aniversário de Manaus, a cenografia desse discurso seguiu a encenação de homenagem. Por isso, ele não segue a cenografia mais prototípica dos anúncios do ramo imobiliário, que seria uma cena urbana, com os imóveis em destaque. Opta-se por uma cenografia de felicitação com exploração de belas imagens da natureza, dignas de cartões postais da região. Na dimensão imagética da cenografia, os aspectos da natureza são valorizados, o que representa a "cultura enraizada" a que o discurso se refere.

No entanto, na dimensão verbal, foram evidenciadas as restrições próprias do discurso publicitário, que está inserido na lógica da globalização e da modernidade líquida, como proposta por Bauman (2005, 2013). Na modernidade líquida, são valorizados os padrões de uma cultura globalizada, "moderna" e de uma cultura flexível, fluida, aberta ao consumo. Esse posicionamento está de acordo com a finalidade desse gênero que é: vender produtos ou serviços ou estabelecer padrões da cultura do consumo por mais que se apresente mobilizando a cenografia de homenagem/felicitação.

\section{Referências}

A CRÍTICA. Manaus, 24 out. 2010, Especial, p. 32.

BAUMAN, Zygmunt. Identidade: entrevista a Benedetto Vecchi. Trad. Carlos Alberto Medeiros, Rio de Janeiro: Zahar, 2005.

. A cultura no mundo líquido moderno. Trad. Carlos Alberto Medeiros, Rio de Janeiro: Zahar, 2013.

CASTRO, Carlos Potiara. O conceito de sustentabilidade na teoria 
social latino-americana: uma análise preliminar. In: FERREIRA, Leila da Costa (Org.). A questão ambiental na América Latina. Campinas: Editora da Unicamp, 2011. p. 189-206.

LOPES, Júlio Antônio. A Crítica de Umberto Calderaro Filho. Manaus: Cultural da Amazônia, 2010.

MAINGUENEAU, Dominique. Novas tendências em análise do discurso. Trad. Freda Indursky. Campinas: Pontes, 1997.

. Diversidade dos gêneros de discurso. In: MACHADO, Ida Lúcia; MELLO, Renato. Gêneros: reflexões em análise do discurso. Belo Horizonte: UFMG, 2004. p. 43-58.

. Gênese dos discursos. Trad. Sírio Possenti. São Paulo: Parábola, 2008a.

. Cenas de enunciação. Sírio Possenti; Maria Cecília Pérez de Souza-e-Silva (Orgs.). São Paulo: Parábola, 2008b.

. Análise de textos de comunicação. 6. ed. ampl. Trad. Maria Cecília Pérez de Souza-e-Silva; Décio Rocha. São Paulo: Cortez, 2013.

. Discurso e análise do discurso. Trad. Sírio Possenti. São Paulo: Parábola, 2015.

ROCHA, Everardo. Representações do consumo: estudos sobre a narrativa publicitária. Rio de Janeiro: PUC-Rio, Mauad, 2006.

WILLIAMS, Raymond. Publicidade o sistema mágico. In:

Cultura e materialismo. Trad. André Glaser. São Paulo: UNESP, 2011. p. 231-266. 